\title{
Pervaporation separation of $n$-heptane/sulfur species mixtures with polydimethylsiloxane membranes
}

\author{
Changwei Zhao ${ }^{\mathrm{a}, *}$, Jiding $\mathrm{Li}^{\mathrm{b}}$, Rongbin $\mathrm{Qi}^{\mathrm{b}}$, Jian Chen ${ }^{\mathrm{b}}$, Zhaokun Luan ${ }^{\mathrm{a}}$ \\ a State Key Laboratory of Environmental Aquatic Chemistry, Research Center for Eco-Environmental Sciences, Chinese Academy of Sciences, \\ P.O. Box 2871, Beijing 100085, China \\ b Department of Chemical Engineering, Tsinghua University, Beijing 100084, China
}

\section{A R T I C L E I N F O}

\section{Article history:}

Received 25 October 2007

Received in revised form 21 March 2008

Accepted 6 May 2008

\section{Keywords:}

Sulfur removal

Pervaporation

Gasoline

Polydimethylsiloxane membranes

\begin{abstract}
A B S T R A C T
With the mixtures of $n$-heptane and different sulfur species making up the model gasoline, polydimethylsiloxane (PDMS)/polyetherimide (PEI) composite membranes were prepared and used for sulfur removal from gasoline. Effects of sulfur species, feed sulfur content and feed temperature on the desulfurization efficiency were investigated for a series of binary $n$-heptane/sulfur species mixtures by pervaporation. Experimental results indicated that the change of feed sulfur content produced insignificant effect on sulfur enrichment factor for every sulfur species, while the partial fluxes of sulfur species were proportional to feed sulfur content. With the feed temperature increase, total flux increased for every binary mixture. Sulfur enrichment factor decreased in the following order at the same temperature: thiophene $>2$-methylthiophene $>2$,5-dimethylthiophene $>$ n-butyl mercaptan $>$ n-butyl sulfide Correspondingly activation energy of permeation was also obtained. In order to simulate the desulfurization process of real gasoline, effect of more sulfur species coupling exist on separation efficiency was also investigated. With the increase of sulfur species number according to the decrease order of sulfur enrichment factor, total sulfur enrichment factor decreased while total flux was almost invariable.
\end{abstract}

Crown Copyright $\odot 2008$ Published by Elsevier B.V. All rights reserved.

\section{Introduction}

Environmental concerns have resulted in the legislation of low sulfur content in gasoline. Among commercial gasoline, fluid catalytic cracking (FCC) gasoline is the most important source of sulfur. Refiners worldwide are rushing to develop their strategy for economically and reliably meeting clean fuel regulation. In recent years, pervaporation (PV) has been proven to be a feasible technology with a number of potential advantages over conventional sulfur removal process from gasoline [1,2]. Polydimethylsiloxane (PDMS) is the most interesting and promising polymetric membrane materials and has been extensively investigated for the separation of different mixtures by PV [3,4].

In previous work on the desulfurization from gasoline [5-13], research works were mainly concentrated on the separation of hydrocarbon/thiophene mixtures. However, FCC gasoline is an extraordinarily complex mixture composed of hundreds of compounds. It is necessary to investigate the different gasoline components on separation performance. Sulfur compounds in gasoline are also important investigation subject for FCC gaso-

\footnotetext{
* Corresponding author. Tel.: +86 10 62849198; fax: +86 1062849198 .

E-mail address: zhaocw@rcees.ac.cn (C. Zhao).
}

line desulfurization technology. Little has been reported on the influence of sulfur species in FCC gasoline on membrane performance for FCC gasoline desulfurization. Typical sulfur compounds in gasoline were thiophene species, mercaptans and sulfides [14-16]. Sulfur species will produce considerable effect on pervaporation separation performance. The aim of this paper is to study the effect of various sulfur species on separation performance through PV experiment. In this paper, polydimethylsiloxane (PDMS)/polyetherimide (PEI) composite membranes were prepared and employed in pervaporation separation on different systems of $n$-heptane/sulfur species mixtures at laboratory scale. A series of sulfur species, namely thiophene, 2-methylthiophene, 2,5-dimethylthiophene, $n$-butyl mercaptan, $n$-butyl sulfide and $n$ heptane as the representative alkane were chosen to simulate model gasoline. Effects of sulfur content, feed temperature and sulfur species number on the sulfur removal efficiency were investigated experimentally.

\section{Experimental}

\subsection{Materials}

Polyetherimide (PEI) Ultem ${ }^{\circledR} 1000$ (General Electric Plastics) was dried at $150^{\circ} \mathrm{C}$ for $8 \mathrm{~h}$ before used. Polydimethylsiloxane 


\begin{tabular}{|ll|}
\hline Nomenclature \\
$A$ & area of the membrane $\left(\mathrm{m}^{2}\right)$ \\
$E_{\mathrm{p} i}$ & activation energy of permeation for component $i$ \\
& $(\mathrm{~kJ} / \mathrm{mol})$ \\
$J, J_{i}$ & total flux and partial flux of component $i\left(\mathrm{~kg} /\left(\mathrm{m}^{2} \mathrm{~h}\right)\right)$ \\
$m$ & weight of permeate $(\mathrm{kg})$ \\
$P_{i}$ & permeability of component $i\left(\mathrm{~m}^{2} / \mathrm{h}\right)$ \\
$P_{i 0}$ & pre-exponential factor $\left(\mathrm{m}^{2} / \mathrm{h}\right)$ \\
$R$ & gas constant \\
$t$ & permeating time $(\mathrm{h})$ \\
$T$ & temperature $(\mathrm{K})$ \\
$\omega_{i}^{\mathrm{F}}$ & weight fraction of component $i$ in the feed \\
$\omega_{i}^{\mathrm{P}}$ & weight fraction of component $i$ in the permeate \\
\hline
\end{tabular}

(PDMS) (viscosity 10 Pa s), ethyl orthosilicate, dibutyltin dilaurate, $n$-heptane and $N, N$-dimethyl acetamide (DMAc) (analytical grade, Beijing Chemical Company, China) were used for the preparation of PDMS/PEI composite membranes. Different sulfur species, i.e., thiophene (99\% mass pure, Acros), 2-methylthiophene (98\% mass pure, Acros), 2,5-dimethylthiophene (98.5\% mass pure, Acros), $n$ butyl mercaptan (99\% mass pure, Acros) and $n$-butyl sulfide (99\% mass pure, Acros), $n$-heptane (Beijing Chemical Company, China) were chosen as the representative alkane compound to make up the model gasoline. Some properties of $n$-heptane, thiophene, 2methylthiophene, 2,5-dimethylthiophene, $n$-butyl mercaptan and $n$-butyl sulfide are listed in Table 1.

\subsection{Membrane preparation}

Firstly, porous polyetherimide (PEI) membrane was prepared with the phase inversion technique. PEI was dissolved in DMAc solvent at $353.15 \mathrm{~K}$ until a homogenous solution was obtained. After filtration, degassed under vacuum, the casting solution was cast onto a polyester non-woven fabric with the aid of a casting knife made in this laboratory. The cast film was immediately immersed into a coagulation bath, then membrane was washed in de-ionized water thoroughly and air-dried completely at ambient temperature. Secondly, PDMS prepolymer, crosslinking agent ethyl orthosilicate and initiator dibutyltin dilaurate were dissolved into $n$-heptane at room temperature. After degassed under vacuum, the solution was cast onto the PEI membrane to form the skin layer. Then the composite membranes were vulcanized under room temperature to evaporate the solvent, after introduced into a vacuum oven to complete crosslinking. The morphology of the membranes was observed by a scanning electron microscope (SEM) (Hitachi S-450). The thickness of the top skin layer of the membranes was determined by SEM photograph. All experiments in this study were performed with the same membrane.

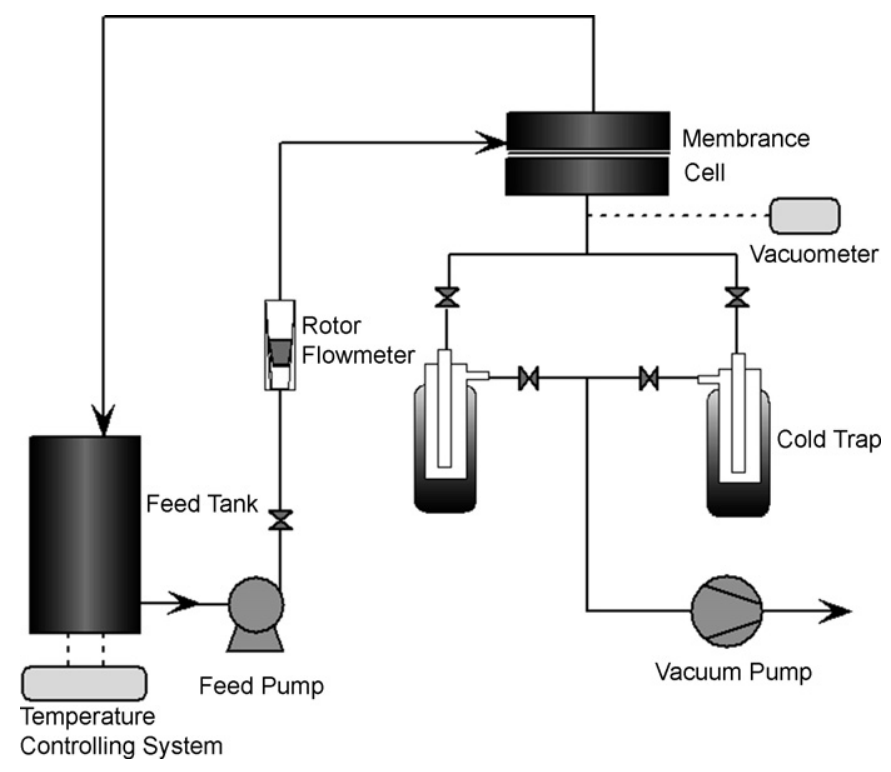

Fig. 1. Schematic setup of the laboratory pervaporation unit.

\subsection{Separation performance measurement}

As shown schematically in Fig. 1, the membrane module is a annular chamber made of stainless steel, in which a membrane supported by a porous sintered stainless steel in the permeate side was mounted. The effective area of the membrane was $2.83 \times 10^{-3} \mathrm{~m}^{2}$. The feed liquid, contained in a $2.5 \times 10^{-3} \mathrm{~m}^{3}$ heated tank, was pumped through the feed compartment of the membrane cell, where it came into direct contact with the PDMS top layer of the membrane. The feed solution was maintained in the temperature range of 323.15-363.15 K using a thermostat. Vacuum on the permeate side was kept below $400 \mathrm{~Pa}$ and was monitored with a digital vacuometer. Steady state fluxes were determined by condensing and freezing the permeate vapor in two cold traps, which were set in parallel and used alternatively in order to collect permeate without rupture of the vacuum. Total flux and partial flux are calculated through the following equations:

$J=\frac{m}{A t}$

and

$J_{i}=\omega_{i}^{\mathrm{P}} J$

with $J$ and $J_{i}$ denoting total flux and partial flux of component $i, m$ the weight of permeate passing through the active membrane area $A$ during the time $t, \omega_{i}^{\mathrm{P}}$ the weight fraction of component $i$ in the permeate.

The feed and permeate compositions were analyzed by gas chromatography (HP6890, USA). For both binary and multicompo-

Table 1

Representative properties of the n-heptane and sulfur species

\begin{tabular}{|c|c|c|c|c|c|c|}
\hline & \multicolumn{6}{|l|}{ Compound } \\
\hline & $n$-Heptane & Thiophene & 2-Methylthiophene & 2,5-Dimethyl thiophene & $n$-Butyl mercaptan & n-Butyl sulfide \\
\hline Structural formula & $\mathrm{CH}_{3}\left(\mathrm{CH}_{2}\right)_{5} \mathrm{CH}_{3}$ & & & $\mathrm{CH}_{3}^{\prime}$ & $\mathrm{CH}_{3}\left(\mathrm{CH}_{2}\right)_{3} \mathrm{SH}$ & {$\left[\mathrm{CH}_{3}\left(\mathrm{CH}_{2}\right)_{3}\right]_{2} \mathrm{~S}$} \\
\hline $\mathrm{fp}\left({ }^{\circ} \mathrm{C}\right)$ & -4 & -9 & 7 & 23 & 12 & 76 \\
\hline $\mathrm{mp}\left({ }^{\circ} \mathrm{C}\right)$ & -91 & -38 & -63 & - & -116 & -80 \\
\hline $\mathrm{bp}\left({ }^{\circ} \mathrm{C}\right)$ & 98 & 84 & 113 & 135 & 98 & 188 \\
\hline Density at $20^{\circ} \mathrm{C}\left(\mathrm{kg} / \mathrm{m}^{3}\right)$ & 680 & 1050 & 1020 & 984 & 840 & 830 \\
\hline
\end{tabular}



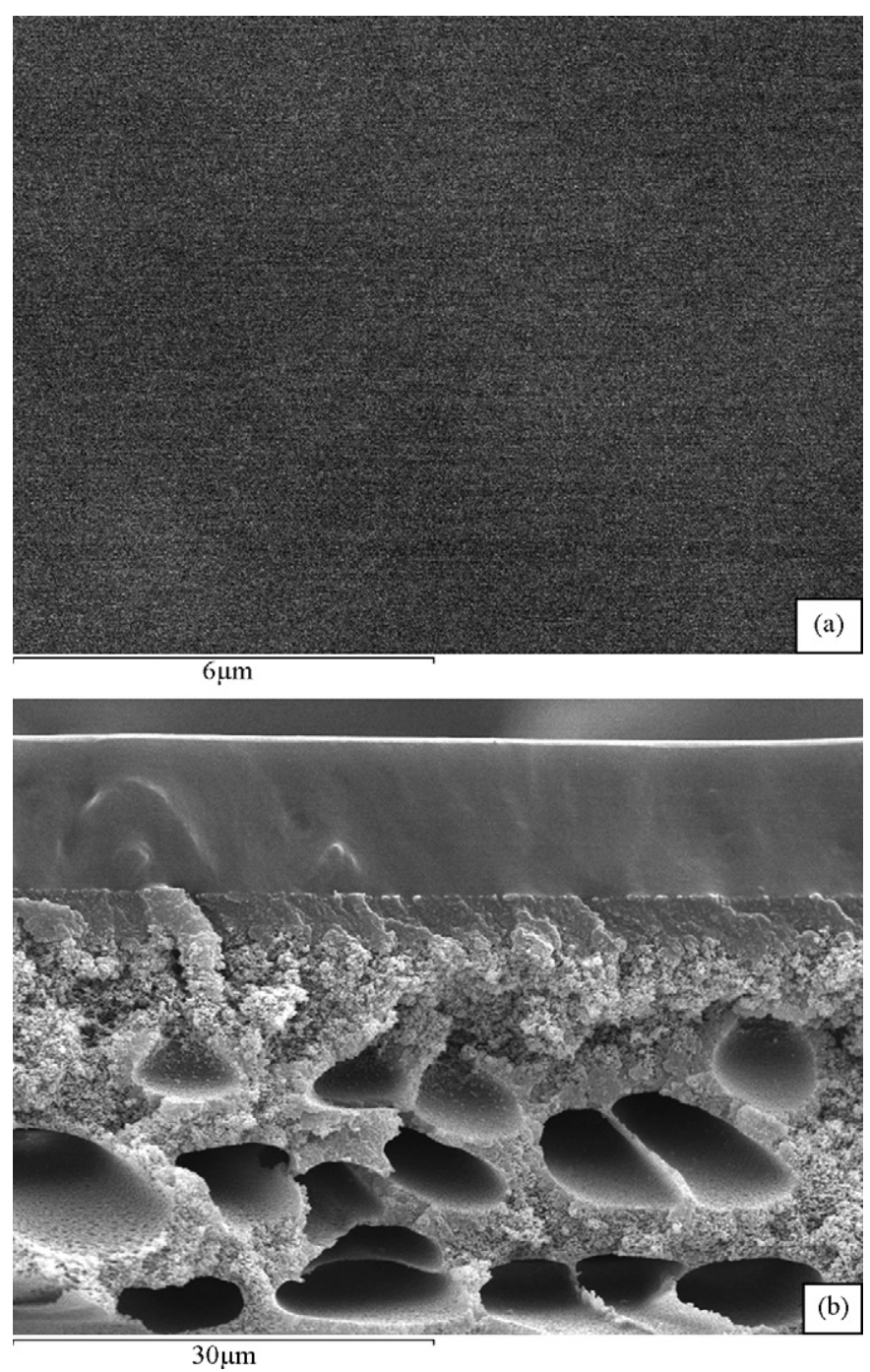

Fig. 2. SEM photographs of PDMS/PEI membranes: (a) top surface $10000 \times$ and (b) cross-section $2000 \times$.

nent systems the sulfur enrichment factor $k_{i}$ defined as follows is adopted to characterize the separation performance of the membrane:

$k_{i}=\frac{\omega_{i}^{\mathrm{P}}}{\omega_{i}^{\mathrm{F}}}$

where $k_{i}$ is the sulfur enrichment factor for component $i, \omega_{i}^{\mathrm{F}}$ refers to the weight fraction of component $i$ in the feed.

\section{Results and discussion}

\subsection{SEM photographs of PDMS/PEI composite membranes}

The SEM morphology of the PDMS/PEI membranes is shown in Fig. 2. From Fig. 2(a), we can see that the top PDMS layer, functioning as the basis of perselectivity, had a dense and tight structure. Fig. 2(b) shows the originally porous surface of the PEI substrate is covered by a flat featureless PDMS layer. The thickness of the PDMS layer was determined to be $11 \mu \mathrm{m}$ from the SEM photograph of cross-section of the membranes.

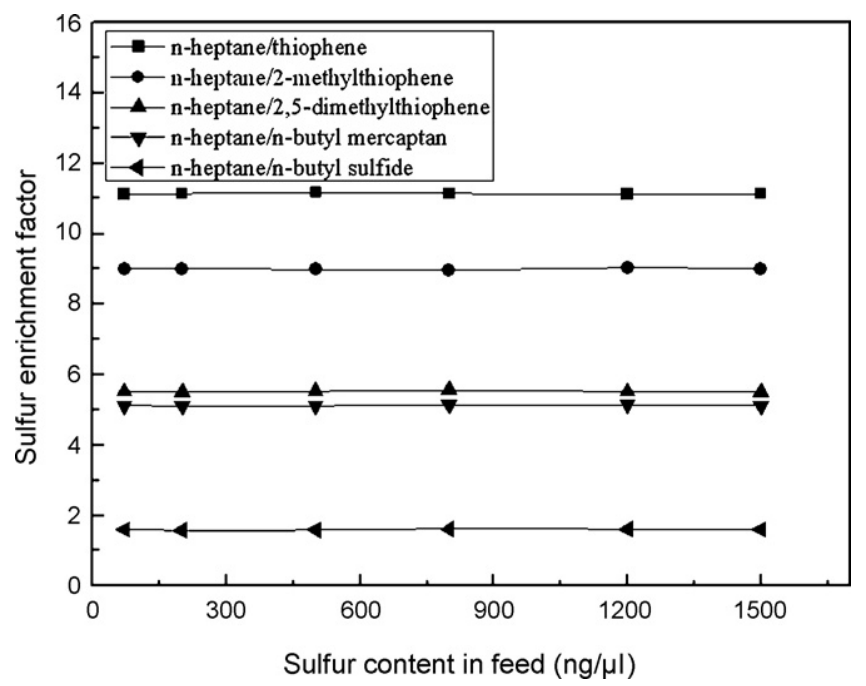

Fig. 3. Effect of feed sulfur content on sulfur enrichment factor for binary nheptane/sulfur mixtures.

\subsection{Effect of feed sulfur content on pervaporation properties}

The gasoline is a rather complex mixture containing various sulfur species. A series of sulfur species (thiophene, 2-methylthiophene, 2,5-dimethylthiophene, $n$-butyl mercaptan and $n$-butyl sulfide) were selected to investigate the sulfur removal efficiency from the $n$-heptane/sulfur species mixtures with PDMS/PEI composite membranes. Fig. 3 shows the influence of the feed sulfur content on sulfur enrichment factor for different binary $n$-heptane/sulfur mixtures at the feed temperature of $353.15 \mathrm{~K}$. It can be seen that variation of feed sulfur content had nearly negligible influence on sulfur enrichment factor for every sulfur species. As shown in Fig. 4, partial fluxes of sulfur species are proportional to the feed sulfur content. According to the solution-diffusion theory, the separation performance of this process is dominated by the sorption and diffusion characteristics of the individual component. The feed processed in this work is an ultra composition-asymmetric mixture, that is, the sulfur content was very low and fell into a relatively narrow range. On one hand, the change in sulfur content in the feed yields very limited impact on the transport of n-heptane through the membrane. On the other hand, the partial fluxes of sul-

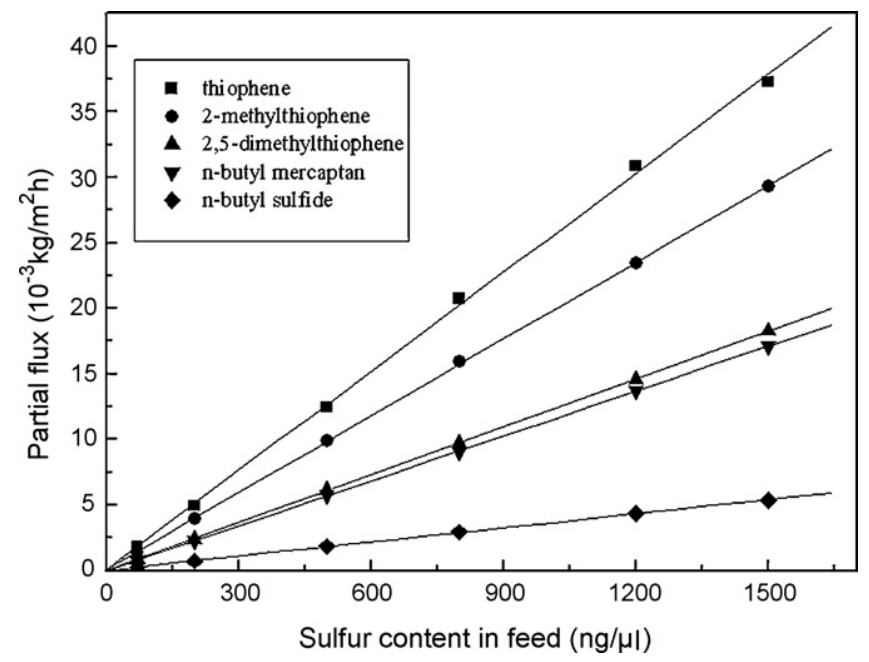

Fig. 4. Dependence of partial fluxes on feed sulfur content for binary nheptane/sulfur mixtures. 


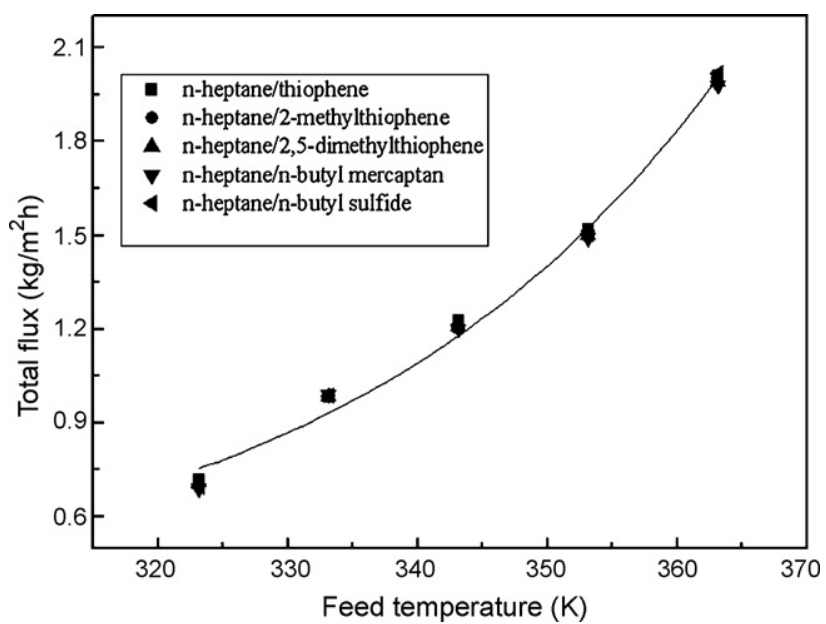

Fig. 5. Dependence of total flux on feed temperature for binary $n$-heptane/sulfur mixtures.

fur species are still proportional to the sulfur content in the feed, which leads to nearly unchanged selectivity to sulfur species.

\subsection{Effect of feed temperature on pervaporation properties}

Fig. 5 shows the effect of feed temperature on total flux in different binary mixtures with $500 \mathrm{ng} / \mu \mathrm{l}$ sulfur content level in the feed. As expected, the total flux for every binary system increases with the feed temperature increase. This can be explained that temperature increase enhances mobility of both polymer segments which offers more free volume for permeating molecules to occupy and permeating molecules which facilitate their movement within the membrane. The feed mixtures in this work are ultra compositionasymmetric mixtures composed of high $n$-heptane content and very low sulfur species content. The variation of sulfur species content in binary feed yields very limited impact on the transport of $n$-heptane through the membrane, which results in nearly unchanged total flux at the same temperature.

Transport performance of molecule $i$ through dense membrane can be expressed according to solution-diffusion model:

$J_{i}=\frac{P_{i} C_{i}^{\mathrm{F}}}{\delta}$

where $J_{i}$ is the flux of component $i, C_{i}^{\mathrm{F}}$ is the concentration of component $i$ in liquid bulk, $\delta$ the thickness of the dense membrane and $P_{i}$ the permeability of component $i$.

According to Arrhenius relationship the permeability $P_{i}$ with temperature is described as the following:

$P_{i}=P_{i 0} E^{-E_{\mathrm{p} i} / R T}$

where $P_{i 0}$ is the pre-exponential factor, $E_{\mathrm{p} i}$ the activation energy of permeation for component $i, T$ the feed absolute temperature and $R$ the gas constant.

Dependence of permeability of different sulfur species on temperature is shown in Fig. 6. It can be found that, as a

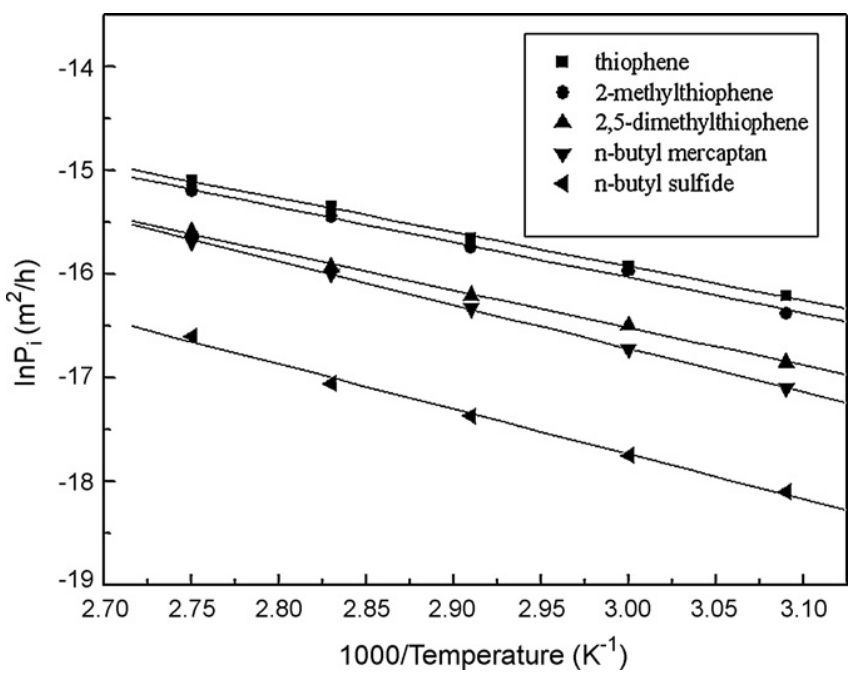

Fig. 6. Sulfur species permeability profiles of binary $n$-heptane/sulfur mixtures with feed temperature.

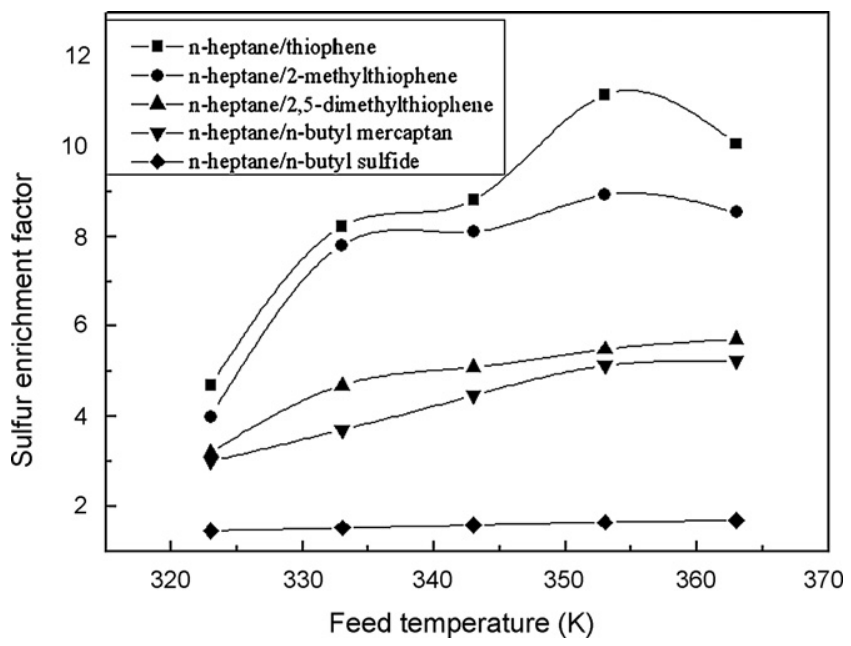

Fig. 7. Temperature dependence of sulfur enrichment factor of sulfur species for binary $n$-heptane/sulfur mixtures.

consequence of the difference in molecular size, the permeability of sulfur species decreases in the following order: thiophene $>2$-methylthiophene $>2$,5-dimethylthiophene $>n$-butyl mercaptan $>n$-butyl sulfide. Without exception, the permeability of pervaporation decreases exponentially with reciprocal of temperature following equation (5). By curving fitting of the experimental data, the pre-exponential factor and the activation energy of permeation $E_{\mathrm{p} i}$ for the individual components are calculated and summarized in Table 2 .

Fig. 7shows the effect of feed temperature on sulfur enrichment factor for different binary $n$-heptane/sulfur species mixtures. Sulfur enrichment factors of thiophene and 2-methylthiophene

Table 2

Activation energies and permeability correlations of individual components

\begin{tabular}{|c|c|c|c|}
\hline Sulfur species & $P_{i 0},\left(\mathrm{~m}^{2} / \mathrm{h}\right)$ & Activation energy, $E_{p i}(\mathrm{~kJ} / \mathrm{mol})$ & Permeability correlation \\
\hline Thiophene & $2.33 \times 10^{-3}$ & 27.29 & $\ln P_{i}=-6.0631-3283.6 / T$ \\
\hline 2-Methylthiophene & $3.00 \times 10^{-3}$ & 28.31 & $\ln P_{i}=-5.8097-3403.8 / T$ \\
\hline 2,5-Dimethylthiophene & $3.41 \times 10^{-3}$ & 29.98 & $\ln P_{i}=-5.6801-3607.8 / T$ \\
\hline n-Butyl mercaptan & $9.91 \times 10^{-3}$ & 33.53 & $\ln P_{i}=-4.6147-4032.6 / T$ \\
\hline$n$-Butyl sulfide & $1.36 \times 10^{-2}$ & 37.11 & $\ln P_{i}=-4.2917-4463.1 / T$ \\
\hline
\end{tabular}




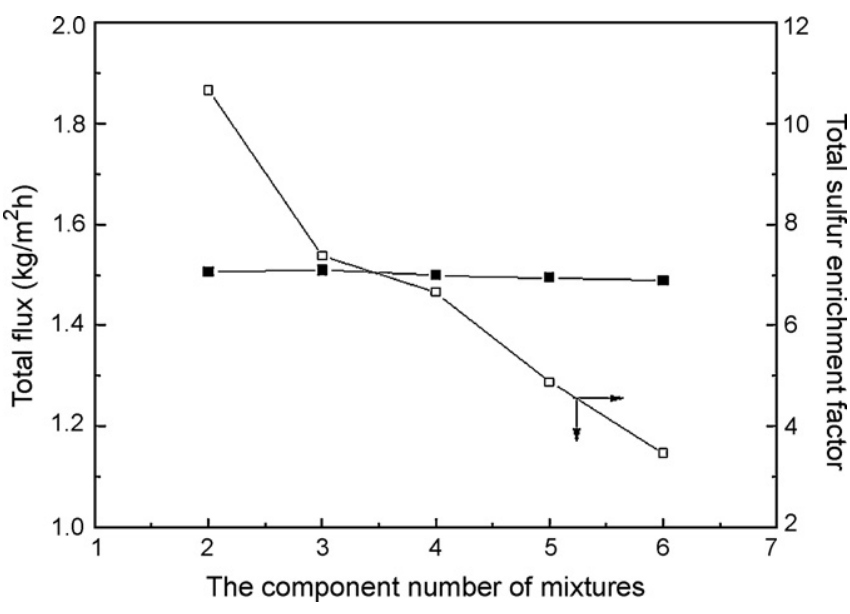

Fig. 8. The influence of the number of sulfur species on pervaporation performance (two component: $n$-heptane + thiophene $(500 \mathrm{ng} / \mu \mathrm{l}$ ); three component: $n$-heptane + thiophene $(250 \mathrm{ng} / \mu \mathrm{l})+2$-methylthiophene $(250 \mathrm{ng} / \mu \mathrm{l})$; four component: $n$-heptane + thiophene $(250 \mathrm{ng} / \mu \mathrm{l})+2$-methylthiophene $(125 \mathrm{ng} / \mu \mathrm{l})+2,5$-dimethylthiophene $(125 \mathrm{ng} / \mu \mathrm{l})$; five component: $n$-heptane + thiophene $(250 \mathrm{ng} / \mu \mathrm{l})+2$-methylthiophene $(85 \mathrm{ng} / \mu \mathrm{l})+2,5$-dimethylthiophene $85 \mathrm{ng} / \mu \mathrm{l})+n$-butyl mercaptan $(80 \mathrm{ng} / \mu \mathrm{l})$; six component: $n$-heptane + thiophene $(250 \mathrm{ng} / \mu \mathrm{l})+2$-methylthiophene $(62 \mathrm{ng} / \mu \mathrm{l})+2,5$-dimethylthiophene $(62 \mathrm{ng} / \mu \mathrm{l})+$ $n$-butyl mercaptan $(62 \mathrm{ng} / \mu \mathrm{l})+n$-butyl sulfide $(62 \mathrm{ng} / \mu \mathrm{l}))$.

increase firstly but decrease after $353.15 \mathrm{~K}$ similar to results [7,10], those of 2,5-dimethythiophene and $n$-butyl mercaptan increase with the feed temperature increase in the studied temperature range, $n$-butyl sulfide almost remains level line. The sulfur enrichment factor of every sulfur species decreases in the following order at the same temperature: thiophene $>2$-methylthiophene $>2,5$ dimethylthiophene $>n$-butyl mercaptan $>n$-butyl sulfide. It is evident that sulfur enrichment factor of thiophene is higher than that of 2-methylthiophene and 2,5-dimethylthiophene due to the difference of the molecular size and structure shown in Table 1 . From the viewpoint of solution-diffusion theory, both the differences in sorption and diffusion of the species in the membrane might be contributing factors to this situation. Numerous researchers have reported that the increase in penetrant size will lead to a decrease in diffusivity. In rubbery PDMS polymer, increasing penetrant size tends to improve the heat of sorption, which would facilitate the generation of sites for permeant molecules to occupy. It follows that larger permeant molecules would be readily sorbed. Consequently, the overall effect of the permeant on the transport would be a balance between an increased solubility and a decreased diffusivity. The experimental results indicated that, with the increase in molecular size of sulfur species, the increase in solubility is traded off by the decrease of the diffusivity, which would result in a smaller sulfur enrichment factor. The nearly level line for $n$-heptane/ $n$-butyl sulfide system indicates that effect of temperature on enrichment factor was little. This is mainly because of smaller difference in structure for $n$ heptane and $n$-butyl sulfide, in which variation of temperature yields similar impact on the partial flux of $n$-heptane and $n$-butyl sulfide.

\subsection{Effect of sulfur species number on pervaporation properties}

In order to simulate possibly the desulfurization process of real gasoline, effect of more sulfur species coupling exist on separation efficiency was also investigated. As shown in Fig. 8, at the feed temperature of $353.15 \mathrm{~K}$, total sulfur enrichment factor decreases with the increase of sulfur species number in the feed from one compo- nent to five components according to the decrease order of sulfur enrichment factor. The result is similar to the result of binary $n$ heptane/sulfur mixtures, that is to say, the increase of sulfur species number shows more negative influence on total sulfur enrichment factor.

\section{Conclusions}

Worldwide concerns over environment have stimulated increasing interest both in academic and industry for deep desulfurization of gasoline. PDMS/PEI composite membranes were prepared and used for separation of binary and multicomponent n-heptane/sulfur species which were taken as the model gasoline. It was found that the different sulfur species had significant impact on the desulfurization efficiency. Following conclusions were obtained:

(1) The change of feed sulfur content produced insignificant effect on sulfur enrichment factor for every sulfur species in binary $n$-heptane/sulfur mixtures, while the partial fluxes of sulfur species were proportional to feed sulfur content.

(2) For every binary $n$-heptane/sulfur mixtures, total flux increased with the feed temperature increase. Sulfur enrichment factor decreased in the following order at the same temperature: thiophene $>2$-methylthiophene $>2,5$-dimethylthiophene $>n$ butyl mercaptan $>n$-butyl sulfide. Correspondingly activation energies of permeation for sulfur species in membranes were obtained.

(3) Total sulfur enrichment factor decreased but total flux was almost invariable with the increase of sulfur species number in the feed according to the decrease order of sulfur enrichment factor.

\section{Acknowledgement}

The financial support by Ministry of Science and Technology of China (National 973 Project, No. 2003CB615701) is sincerely appreciated by the authors.

\section{References}

[1] B.S. Minhas, M.R. Chuba, R.J. Saxton et al, Membrane process for separating sulfur compounds from FCC light naphtha, US Patent 6,649,061.

[2] R.J. Saxton, J. Robert, B.S. Minhas, Ionic membranes for organic sulfur separation from liquid hydrocarbon solutions, US Patent 6,702,945.

[3] T. Mohammadi, A. Aroujalian, A. Bakhsai, Pervaporation of dilute alcoholic mixtures using PDMS membrane, Chem. Eng. Sci. 60 (2005) 1875-1880.

[4] A. Hasanoglu, Y. Salt, S. Keleser, et al., Pervaporation separation of ethy acetate-ethanol binary mixtures using polydimethylsiloxane membranes, Chem. Eng. Proc. 44 (2005) 375-381.

[5] L. Lin, G. Wang, H. Qu, et al., Pervaporation performance of crosslinked polyethylene glycol membranes for deep desulfurization of FCC gasoline, J. Membr. Sci. 280 (2006) 651-658.

[6] L. Lin, Y. Kong, G. Wang, et al., Selection and crosslinking modification of membrane material for FCC gasoline desulfurization, J. Membr. Sci. 285 (2006) 144-151.

[7] Y. Kong, L. Lin, J. Yang, et al., FCC gasoline desulfurization by pervaporation: effects of gasoline components, J. Membr. Sci. 293 (2007) 36-43.

[8] L. Lin, Y. Kong, J. Yang, et al., Scale-up of pervaporation for gasoline desulphurisation. Part 1. Simulation and design, J. Membr. Sci. 298 (2007) 1-13.

[9] R. Qi, C. Zhao, J. Li, et al., Removal of thiophenes from $n$-octane/thiophene mixtures by pervaporation, J. Membr. Sci. 269 (2006) 94-100.

[10] R. Qi, Y. Wang, J. Li, et al., Pervaporation separation of alkane/thiophene mix tures with PDMS membrane, J. Membr. Sci. 280 (2006) 545-552.

[11] R. Qi, Y. Wang, J. Li, et al., Sulfur removal from gasoline by pervaporation: the effect of hydrocarbon species, Sep. Purif. Technol. 51 (2006) 258-264.

[12] R. Qi, Y. Wang, J. Chen, et al., Removing thiophenes from n-octane using PDMS-AgY zeolites mixed matrix membranes, J. Membr. Sci. 295 (2007) 114-120.

[13] R. Qi, Y. Wang, J. Chen, et al., Pervaporative desulfurization of model gasoline with $\mathrm{Ag}_{2} \mathrm{O}$-filled PDMS membranes, Sep. Purif. Technol. 57 (2007) 170-175. 
[14] A. Stumpf, K. Tolvaj, M. Juhasz, Detailed analysis of sulfur compounds in gasoline range petroleum products with high resolution gas chromatography atomic emission detection using group selective chemical treatment, J. Chromatogr. A 819 (1998) 67-74

[15] H. Shan, C. Li, Sulfur distribution in FCC gasoline and the research of catalytic desulfurization, J. Univ. Petrol. (China) 25 (2001) 78-80.
[16] P. Leflaive, J.L. Lemberton, G. Perot, et al., On the origin of sulfur impurities in fluid catalytic cracking gasoline-reactivity of thiophene derivatives and of their possible precursors under FCC conditions, Appl. Catal. A 227 (2002) 201-215. 